\title{
Uma breve reflexão sobre o lugar da gastronomia nos estudos sobre turismo realizados no Brasil
}

\section{A short reflection on the gastronomy place in the tourism studies accomplished in Brazil}

\author{
Maria Henriqueta Sperandio Garcia Gimenes (GIMENES, M. H. S. G.) ${ }^{*}$
}

\begin{abstract}
RESUMO - A gastronomia é uma temática de grande destaque na mídia em geral, tendo despertado também o interesse do meio acadêmico, inclusive no contexto do turismo. A partir desta perspectiva, este artigo tem como objetivo realizar uma breve reflexão sobre o lugar da gastronomia nos estudos sobre turismo realizados no Brasil na atualidade, enfatizando a potencialidade do binômio turismo e gastronomia.
\end{abstract}

Palavras-chave: Gastronomia; Turismo; Estudos acadêmicos no Brasil.

ABSTRACT - Gastronomy is a subject of great prominence in the media, and it has also concerned the academia, including in the context of tourism. From this perspective, this paper aims to accomplish a short reflection on the gastronomy place in the studies about tourism in Brazil nowadays, emphasizing the potential of the binomial tourism and gastronomy.

Key words: Gastronomy; Tourism; Academic studies in Brazil.

\section{INTRODUÇÃO}

Escrever um artigo de opinião é uma tarefa desafiadora, pois não se trata de escrever um artigo científico que visa analisar a fundo um determinado tema, mas sim de expressar uma opinião pessoal sobre um determinado tema, lançando, se possível, algumas reflexões. Esta é, pelo menos, a linha que se pretendeu adotar neste texto sucinto.

É consenso que o termo gastronomia atualmente está muito em voga. Seja na televisão (onde programas sobre culinária, protagonizados ou não pelos chefs

\footnotetext{
* Membro do Comitê Científico da Revista Turismo e Sociedade desde janeiro de 2008. Formação: Graduação em Turismo, Mestrado em Sociologia e Doutorado em História pela Universidade Federal do Paraná (UFPR). Professora do Curso de Turismo da Universidade Federal de São Carlos (UFSCAR) Campus Sorocaba. Endereço para correspondência: Rua Teixeira da Silva, 328, ap. 62A (Bairro Paraíso). CEP: 04002-031 - São Paulo - SP (Brasil). Email: mariegimenes@gmail.com
} 
celebridade, preenchem a programação de canais abertos e fechados), nas bancas de jornal (nas inúmeras revistas voltadas para cozinheiros do dia-a-dia, ocasionais e gourmets; ou nos cadernos semanais dedicados ao tema integrantes dos principais jornais do país), e até mesmo no universo virtual (em websites, blogs e comunidades virtuais mantidas por entidades, profissionais da área e até mesmo curiosos), nunca " $a$ arte de comer e beber bem" esteve tão popular. O crescimento de cursos superiores (bacharelados e tecnólogos) em gastronomia também pode ser considerado um indício deste interesse crescente, assim como a expansão do Restaurant Week ${ }^{1}$ para cidades fora do eixo Rio-São Paulo.

A relação da gastronomia e dos serviços a ela dedicados com o turismo sempre foi evidente. Primeiramente, como serviço indispensável para a subsistência e permanência do visitante em uma localidade e, de forma mais contemporânea, como importantes atrativos turísticos e elementos fundamentais para a complementação da oferta de entretenimento de núcleos receptores. Atualmente, a gastronomia é um elemento importante no contexto do Turismo Cultural, permitindo ao visitante se aproximar da localidade visitada, vivendo experiências sensoriais e também culturais.

Se a gastronomia vem despertando interesse do público geral e também tem crescido em importância no desenvolvimento de destinos turísticos, vale questionar como a academia, em especial a ala dedicada ao estudo do turismo, tem reagido ao crescimento da importância da temática. Esta perspectiva é objeto deste breve texto que, mais do que descrever uma realidade, tem como objetivo lançar algumas reflexões para se iniciar um debate.

\section{GASTRONOMIA, UMA ÁREA EM EXPANSÃO}

No que consiste, então, a gastronomia? Embora atualmente seja utilizada também como uma designação de mercado (envolvendo os estabelecimentos dedicados

\footnotetext{
${ }^{1}$ Evento que surgiu em 1993 na cidade de Nova York (Estados Unidos da América) e que consiste na oferta em um determinado período do ano de cardápios especiais (uma entrada, prato principal e sobremesa) para almoço e/ou jantar, vendidos a preços fixos praticados por todos os estabelecimentos participantes. Atualmente o Restaurant Week ocorre no Brasil em Belo Horizonte (MG), Brasília (DF), Curitiba (PR), Fortaleza (CE), Goiânia (GO), Porto Alegre (RS), Rio de Janeiro (RJ), Salvador (BA) e São Paulo (SP), além do estado do Espírito Santo (ES).
} 
à alimentação fora do lar, em suas inúmeras segmentações), a gastronomia surge inicialmente como uma área de conhecimento. Enquanto a alimentação diz respeito, genericamente, ao ato de alimentar-se e ingerir nutrientes, a gastronomia tem um sentido mais específico. Se for feita uma análise sob o ponto de vista etimológico, terse-á que gastronomia (gáster: estômago; nómos: conhecimento ou lei) designa "o conhecimento das leis do estômago".

Seguindo a mesma linha de raciocínio, Maria Lucia Gomensoro (1999, p. 195), estabelece que a gastronomia diz respeito "à arte do bem comer e do saber escolher a melhor bebida para acompanhar a refeição". De forma contemporânea, considerando a complexidade e amplitude do tema, a gastronomia passou a ser compreendida como o estudo das relações entre a cultura e a alimentação, incluindo os conhecimentos das técnicas culinárias, do preparo, da combinação e da degustação de alimentos e bebidas, e ainda dos aspectos simbólicos e subjetivos que influenciam e orientam a alimentação humana (GIMENES, 2010).

A gastronomia, desta forma, se relaciona a um conjunto de saberes e práticas que extrapola a mera ingestão de calorias ou o simples aspecto técnico da preparação de alimentos. Fala-se de cultura, de técnicas de preparo, de formas de serviços e degustação e de todo um universo permeado pelo sabor. Trabalhar com gastronomia no âmbito do turismo significa, portanto, explorar todos esses nuances e matizes. O que tem se tornado cada vez mais importante, face às tentativas de compreender o consumidor turístico no contexto da economia da experiência, aspecto que tem sido muito discutido atualmente.

Para aqueles que vivem em cidades de médio e grande porte, é fácil perceber que bares, restaurantes e similares já fazem parte da paisagem urbana há muitos anos. $\mathrm{O}$ aumento do número de estabelecimentos - mesmo em mercados voláteis, onde muitos empreendimentos fecham antes de completar seu quinto aniversário - é um movimento do mercado diante das mudanças no perfil de consumo alimentar da população, que frequenta bares, restaurantes e similares para alimentar-se (incluindo aqui refeições até então feitas exclusivamente domésticas, como o café-da-manhã), descontrair-se, entreter-se, conhecer pessoas, encontrar amigos e familiares, dentre outras tantas atividades que poderiam ser aqui elencadas. Se frequentar estes espaços é uma necessidade, uma praticidade e também uma forma de lazer incorporada no cotidiano 
das pessoas, pensar este tipo de consumo no contexto do turismo é ainda mais instigante.

Os estudos voltados para o binômio turismo-gastronomia podem ser realizados a partir dos mais diferentes vieses, tomando corpo a partir das mais diversas metodologias. A gestão e o consumo de bares, restaurantes e similares (em seus mais diversos aspectos); o papel destes estabelecimentos na oferta de lazer e entretenimento de um destino turístico; a questão dos pratos típicos (envolvendo aspectos concernentes às tradições alimentares) e seu uso turístico; o desenvolvimento de polos de turismo gastronômico propriamente ditos e ainda as várias formas de operacionalização de atrativos gastronômicos (a partir de acontecimentos programados e rotas e roteiros, dentre outros), são algumas das muitas maneiras de se abordar o binômio.

Contudo, cabe refletir sobre qual é o lugar, o espaço ocupado pela gastronomia nos estudos sobre turismo no Brasil na atualidade. Analisando o mercado editoral nacional, verifica-se que, mesmo diante da existência de inúmeros livros com a temática gastronomia $^{2}$, muitos destes produzidos a partir de olhares advindos da história, da antropologia e da sociologia, poucos são os títulos publicados que exploram sua relação com o turismo. No website de uma das principais livrarias do país, ao se introduzir as palavras "gastronomia", "alimentação" e "turismo" na ferramenta de busca apenas 4 títulos nacionais são indicados. Sabe-se que outros livros possuem capítulos dedicados à temática e que este número não representa a totalidade de publicações, mas ainda assim este número chama à ponderação.

No que tange aos eventos acadêmicos, deve-se salientar o Seminário da Anptur (promovido anualmente pela Associação Nacional de Pesquisa e Pós-Graduação em Turismo) e o Semintur (promovido bi-anualmente pela Universidade de Caxias do Sul), que tradicionalmente reservam um espaço para a discussão da temática, com o desenvolvimento de grupos de trabalho específicos. Há, obviamente, discussões dispersas que aparecem na programação de outros eventos importantes da área, mas sem que haja efetivamente a conformação de um grupo de trabalho.

\footnotetext{
${ }^{2}$ Deve ser ressaltada aqui a importância de atuação pioneira da Editora SENAC (Nacional, São Paulo, dentre outras unidades), que mantém o conjunto mais robusto de publicações sobre gastronomia no país, com obras de autores nacionais e internacionais, que discutem o tema a partir dos mais diferentes enfoques, extrapolando os aspectos técnicos de produção.
} 
Outro espaço de divulgação e produção de conhecimento que não se pode deixar de citar é o âmbito dos periódicos científicos. Como indica uma pesquisa realizada durante um projeto de Iniciação Científica da Universidade Federal do Paraná ${ }^{3}$, desde 2005 o número de artigos envolvendo o binômio turismo-gastronomia vem se ampliando, mesmo timidamente, nos periódicos da área de turismo. Da mesma forma, pensando em termos da produção oriunda de programas de mestrado e doutorado, é possível constatar dissertações e teses desenvolvendo a temática em programas das áreas de Turismo e Hospitalidade, bem como em áreas afins, como História e Geografia.

A análise do quadro geral do lugar da gastronomia nos estudos sobre turismo realizados no Brasil pede uma série de levantamentos específicos, alguns deles já em andamento. O que se pretende aqui, como já mencionado nas primeiras linhas, é provocar uma oportunidade de reflexão para professores, alunos e pesquisadores dedicados à área, pois se o mercado vem se ampliando, o interesse da população "leiga" crescido e o número de pesquisadores dedicados à temática aumentando, é preciso ter clareza que a rede de produção de conhecimento sobre turismo e gastronomia ainda está no início de sua construção e precisa ser efetivamente consolidada.

Mesmo diante de tamanha potencialidade, tendo em vista a própria realidade brasileira em termos turísticos e gastronômicos, verifica-se que a discussão da gastronomia no contexto do turismo ainda é vista por muitos como algo acessório, superficial, um tema interessante, mas pouco relevante e/ou sério. $\mathrm{O}$ caminho para a reversão deste quadro reside, na opinião da presente autora, justamente na qualidade das pesquisas realizadas.

Embora uma análise do quadro geral aponte para um adensamento das pesquisas realizadas e muitos trabalhos consistentes estejam sendo executados, ainda é comum de se encontrar fragilidades em dois pontos fundamentais, apontando para a necessidade de revisões bibliográficas mais acuradas, que cubram efetivamente o que está sendo publicado/pesquisado na área; e a necessidade do desenvolvimento de metodologias coerentes com as propostas de cada pesquisa.

\footnotetext{
3 Intitulado "A relação turismo/gastronomia na produção acadêmica brasileira - um estudo exploratório" o projeto foi desenvolvido pelas alunas Clarissa Brandolf Gindri, Franciele Manosso e Juliana Zardo, sob orientação da professora Maria Henriqueta Sperandio Garcia Gimenes. O relatório da pesquisa já foi concluído em julho de 2011 e aprovado, e a adaptação do relatório em artigo científico está sendo realizada.
} 
A preocupação em relação à necessidade de revisões bibliográficas mais adequadas consiste na constatação de que, apesar da já mencionada ampliação de publicações, principalmente em periódicos e em eventos, e a despeito deste rico material estar disponível on line, muitos pesquisadores não recorrem a estas pesquisas $\mathrm{e}$ terminam por repetir, como se estivessem apresentando novidades, assuntos que já estão sendo discutidos há algum tempo. E não se pode esquecer também todo referencial teórico construído na administração; na antropologia, na geografia, na história, na sociologia, dentre outras áreas de conhecimento, que podem e devem ser recuperados e utilizados para uma melhor compreensão da gastronomia e dos serviços a ela relacionados. Esta falta de rigor teórico na construção do referencial teórico também se evidencia no uso de terminologia inadequada, onde conceitos dão lugar ao senso comum e neologismos são criados de forma indiscriminada.

A questão metodológica se põe lado a lado com a questão da discussão teórica. A falta de clareza na descrição das metodologias utilizadas e até mesmo a falta de compatibilidade entre a metodologia escolhida e o objeto/objetivos do estudo não apenas prejudicam a apreciação da análise apresentada por um autor, como também inibem a construção de novas metodologias a partir da revisão de modelos já aplicados, bem como impossibilitam a realização de estudos semelhantes para realidades distintas. Não seria a leitura e análise de artigos e pesquisas publicadas que poderiam refletir com maior acuidade sobre a qualidade do próprio trabalho dos autores/das pessoas? O problema embutido nesta falta de diálogo entre pesquisadores no âmbito teóricometodológico, com pouca interlocução em relação ao que é produzido pelos pares gera não apenas um isolamento entre os sujeitos, mas o próprio atraso na produção do conhecimento para a área, fragilizando o tratamento da temática como um todo.

\section{CONCLUINDO....}

A importância da gastronomia e dos serviços a ela relacionado cresce a olhos vistos, não apenas no âmbito do turismo, mas também do ponto de vista do consumo cotidiano. Com isto, este campo torna-se muito profícuo para a atuação de pesquisadores e também para os próprios bacharéis em turismo, que se movimentam 
pela ampliação das áreas de atuação. É a partir deste panorama, na leitura desta autora um panorama altamente favorável, que se gostaria de lançar aos colegas interessados pelo estudo e pesquisa da gastronomia associada ao turismo duas últimas inquietações.

Se a potencialidade da temática é inegável e há muito a ser desenvolvido, qual é o lugar que se pretende dar à gastronomia no âmbito do turismo? E ainda: como se pode fazer com que isso se efetive? Unir esforços e ampliar o diálogo, assim como o debate, parece ser o primeiro passo para uma série de profícuas ações.

\section{REFERÊNCIAS}

GIMENES, M. H. S. G. Sentidos, sabores e cultura: a gastronomia como experiência sensorial e turística. In: GAETA, C.; PANOSSO NETTO, A. Turismo de experiência. São Paulo: SENAC, 2010.

GOMENSORO, M. L. Pequeno dicionário de gastronomia. Rio de Janeiro: Objetiva, 1999. 